\title{
Retrospective analysis of the effects of continuous intraluminal aspiration on postoperative intestinal fistulas.
}

\author{
Arif Emre*, Mehmet Sertkaya, Emrah Cengiz, Onur Peker, Eyüp Mehmet Pircanoğlu, İlhami Taner \\ Kale, Ahmet Necati Şanlı \\ Faculty of Medicine, Kahramanmaras University, Kahramanmaras, Turkey
}

\begin{abstract}
Aim: The aim of this study was to present the effectiveness of continuous intraluminal aspiration for treating postoperative intestinal fistulas.

Methods: Continuous intraluminal aspiration was conducted on nine patients who underwent surgery for upper or lower Gastrointestinal (GI) tract diseases in our General Surgery clinic from January 2014 to March 2016 and developed an intestinal fistula after the surgery. The clinical and demographic results of the patients were analyzed retrospectively. A double-lumen system consisting of a nasogastric catheter and an implanted endoscopic retrograde cholangiopancreatography cannula was used for aspiration.

Results: Seven of the nine patients (age range: $28-71$ y) were males. Nine patients had complications: six in the upper GI tract and three in the lower GI tract. The first session was technically successful in all patients. Mean hospital stay was $41.77 \pm 15.74 \mathrm{~d}$ and mean aspiration duration was $14.12 \pm 2.84 \mathrm{~d}$. Neoadjuvant chemotherapy (CRT) was performed in four patients. Eight patients recovered and were discharged but one patient, who underwent laparoscopic Ivor Lewis esophagectomy after neoadjuvant CRT for esophageal cancer and developed esophagomediastinal and tracheomediastinal fistulas, died at $20^{\text {th }} \mathrm{d}$ after surgery. Clinical success was achieved in five of six patients $(83 \%)$ who had a fistula and leakage in the upper GI tract, and in three patients (100\%) who had a fistula and leakage in the lower GI tract system.

Conclusions: Although treatment duration is longer when using continuous intraluminal double-lumen catheter aspiration, it is an effective method to treat postoperative intestinal fistulas with a low mortality rate and cost.
\end{abstract}

Keywords: Anastomotic leakage, Intestinal fistula, Intraluminal aspiration.

Accepted on January 23, 2018

\section{Introduction}

Fistulas and anastomotic leakage are complications of surgical attempts to treat benign and malignant diseases of the Gastrointestinal (GI) tract. Various treatments have been used, but surgery is the first-line treatment [1-4]. Today, surgery is still used, but less frequently due to developments in endoscopic technology and assistant's tools. The success of treatments methods that are less invasive and easier than surgery has increased, and reduced complications from these methods have decreased the requirement for surgery remarkably in recent years [5-12]. In this study, we share our experience of patients who received continuous intraluminal aspiration to treat a fistula and anastomotic leakage.

\section{Materials and Methods}

The demographic, clinical, and endoscopic data of nine patients who underwent surgery for upper or lower GI tract diseases at the General Surgery clinic of Kahramanmaraş Sütçü
İmam University Faculty of Medicine from January 2014 to March 2016, and who developed an intestinal fistula or anastomotic leakage after the surgery and received continuous intraluminal aspiration treatment, were analyzed retrospectively. Food consumption was restricted in all patients before the treatment. A double-lumen system using a thinner (5F) lumen Endoscopic Retrograde Cholangiopancreatography (ERCP) cannula, which enabled continuous aspiration and prevented mucosa from sticking during aspiration, was placed inside a soft $18 \mathrm{~F}$ nasogastric catheter. All procedures were conducted using a flexible gastroscope or colonoscope under sedation. The distal end of the system was placed within $1 \mathrm{~cm}$ of where the fistula or leakage developed. Placing the catheter endoscopically at the treatment site was considered a technical success. A low pressure negative vacuum was applied to provide continuous aspiration for $24 \mathrm{~h}$ following placement of the double lumen catheter. The openness of the ERCP cannula used to form the air channel was checked three or four times daily. 


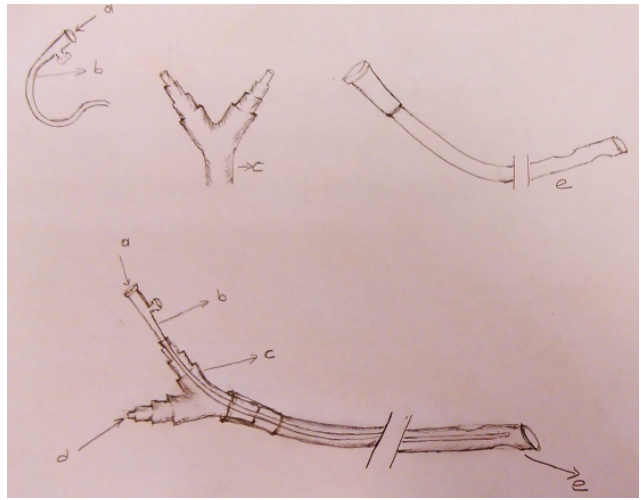

Figure 1. Schematic drawing of the installation of the aspiration system. (a) Air duct; (b) ERCP catheter; (c) Y adaptor separated from the hemovac drain system; (d) Continuous aspiration channel; (e) NG catheter tube.

Any obstructions were removed by injecting $5-10 \mathrm{~mL}$ of normal saline, which was aspirated from the proximal ends of the catheters. Patients did not eat during these procedures. Patients who had a feeding jejunostomy distal to an upper GI fistula were fed enterally and parenterally, whereas total parenteral support treatment was used for patients who did not have a jejunostomy. Patients with a lower GI fistula had a deflector ileostomy and ate normally during the aspiration process. All patients were given wide-spectrum prophylactic antibiotics.

Abscess fluid collected secondary to a fistula, leakage or surgery-causing complications was drained by drains placed using ultrasonography. Ultrasonography or computed tomography was used to determine when no fluid was in the drains, and oral opaque leakage control was done fluoroscopically, the aspiration process was terminated, the drains were removed, and oral intake was started. Oral intake was not started until the upper GI fistulas had completely filled. Healing of the fistula was considered as clinical success (recovery). If the complication continued, surgery was attempted. Any patient who died secondary to a complication was considered a clinical failure.

The medical records were reviewed retrospectively with respect to sex, age, primary disease, surgical method, fistula and/or leakage location, diagnostic method to detect complications, duration of aspiration process (d), total hospitalization duration (d), and treatment success (recovery/ surgery required). The clinical and demographic characteristics of all patients are shown in Table 1 (Figure 1).

On the date of 21st September 2016, approval number 228 was obtained from the Ethics Committee of our faculty for this study.

Table 1. Clinical and demographic characteristics of the patients.

\begin{tabular}{|c|c|c|c|c|c|c|c|c|c|}
\hline Age & Gender & $\begin{array}{l}\text { Primary } \\
\text { disease }\end{array}$ & $\begin{array}{l}\text { Neoadjuvant } \\
\text { chemoradiotherapy }\end{array}$ & Surgery performed & Complications & $\begin{array}{l}\text { Diagnosis of } \\
\text { complication }\end{array}$ & $\begin{array}{l}\text { Aspiration } \\
\text { duration } \\
\text { (d) }\end{array}$ & $\begin{array}{l}\text { Hospital } \\
\text { stay (d) }\end{array}$ & Result \\
\hline 38 & Male & $\begin{array}{l}\text { Gastric } \\
\text { cancer }\end{array}$ & No & $\begin{array}{l}\text { Total gastrectomy and roux } \mathrm{n} y \\
\text { esophagojejunostomy }\end{array}$ & $\begin{array}{l}\text { Esophagojejunostomy } \\
\text { leak+mediastinal } \\
\text { fistula }\end{array}$ & CT+fluoroscopy & 15 & 35 & Recovered \\
\hline 54 & Male & Cholelithiasis & No & Laparoscopic cholecystectomy & $\begin{array}{l}\text { latrogenic duodenal } \\
\text { injury }\end{array}$ & CT+fluoroscopy & 18 & 25 & Recovered \\
\hline 44 & Male & $\begin{array}{l}\text { Duodenal } \\
\text { ulcer } \\
\text { perforation }\end{array}$ & No & $\begin{array}{l}\text { Vagotomy+duodenal artery } \\
\text { ligation+Pyloroplasty+feeding } \\
\text { jejunostomy }\end{array}$ & Duodenal leak & CT+endoscopy & 13 & 60 & Recovered \\
\hline 64 & Female & Rectal cancer & Yes & Low anterior resection & Colo-anal fistula & Rectoscopy & 12 & 51 & Recovered \\
\hline 71 & Male & $\begin{array}{l}\text { Gastric } \\
\text { cancer }\end{array}$ & No & $\begin{array}{l}\text { Total gastrectomy and roux } \mathrm{n} y \\
\text { esophagojejunostomy }\end{array}$ & $\begin{array}{l}\text { Esophagojejunostomy } \\
\text { leak }\end{array}$ & CT+fluoroscopy & 11 & 61 & Recovered \\
\hline 55 & Male & Rectal cancer & Yes & Low anterior resection & Colo-anal fistula & Rectoscopy & 17 & 62 & Recovered \\
\hline 68 & Male & $\begin{array}{l}\text { Gastric } \\
\text { cancer }\end{array}$ & No & $\begin{array}{l}\text { Total gastrectomy and roux } \mathrm{n} y \\
\text { esophagojejunostomy }\end{array}$ & $\begin{array}{l}\text { Esophagojejunostomy } \\
\text { leak }\end{array}$ & CT & 10 & 32 & Recovered \\
\hline 28 & Male & $\begin{array}{l}\text { Esophageal } \\
\text { cancer }\end{array}$ & Yes & Ivor Lewis Esophagectomy & $\begin{array}{l}\text { Esophagotracheal } \\
\text { and } \\
\text { esophagomediastinal } \\
\text { fistula }\end{array}$ & CT & 13 & 20 & Died \\
\hline 56 & Female & Rectal cancer & Yes & Low anterior resection & Colo-anal fistula & Rectoscopy & 17 & 30 & Recovered \\
\hline
\end{tabular}




\section{Results}

Data of nine consecutive patients (seven $(78 \%)$ males and two (22\%) females; age range: $28-71 \mathrm{y}$; mean \pm SD: $53.11 \pm 13.39$ y) were analyzed retrospectively.

Nine patients suffered complications; three had esophagojejunostomy leakage after gastric cancer surgery, one developed esophagomediastinal and tracheomediastinal fistulas after an Ivor Lewis esophagectomy was performed for esophageal cancer, one developed leakage in the pyloroplasty line after a duodenotomy due to a bleeding peptic ulcer, one duodenal fistula emerging from the iatrogenic duodenal injury after laparoscopic cholecystectomy, and three had a colo-anal anastomotic leakage after low anterior resection due to rectal cancer in the lower GI tract. Four patients underwent Chemoradiotherapy (CRT). The first session was technically successful in all patients. All patients developed obstructions that were eliminated easily with normal saline injected from the catheter. Mean hospitalization duration was $41.77 \pm 15.74$ d. Mean drainage volume from upper GI tract fistulas before aspiration was $2,700 \mathrm{~mL} / \mathrm{d}$, which was decreased to $650 \mathrm{~mL} / \mathrm{d}$. Abscess pouch volume and necrotic material decreased in patients with rectal cancer. Mean drainage volume from fistulas in lower GI leaks before aspiration was $300 \mathrm{~mL} / \mathrm{d}$, which dropped to $50 \mathrm{~mL} / \mathrm{d}$ (Table 2).

Table 2. Fistula flow, aspiration time, and clinical success rates of the patients.

\begin{tabular}{|c|c|c|c|c|c|}
\hline Patient group & $\begin{array}{l}\text { Number } \\
\text { of } \\
\text { patients }\end{array}$ & $\begin{array}{l}\text { Mean flow } \\
\text { rate of } \\
\text { fistula } \\
\text { prior to } \\
\text { aspiration } \\
(\mathrm{mL})\end{array}$ & $\begin{array}{l}\text { Mean flow } \\
\text { rate of } \\
\text { fistula } \\
\text { after } \\
\text { aspiration } \\
(\mathrm{mL})\end{array}$ & $\begin{array}{l}\text { Mean } \\
\text { duration } \\
\text { of } \\
\text { aspiration } \\
\text { (d) }\end{array}$ & $\begin{array}{l}\text { Clinical } \\
\text { success } \\
\text { rate }(\%)\end{array}$ \\
\hline Upper GIT & 6 & 2700 & 650 & 13.3 & 83 \\
\hline Lower GIT & 3 & 300 & 50 & 15.3 & 100 \\
\hline All patients & 9 & - & - & 13.6 & 89 \\
\hline
\end{tabular}

GIT: Gastrointestinal Tract.

Mean continuous intraluminal aspiration duration (fistula recovery duration) of all eight patients was $14.12 \pm 2.84 \mathrm{~d}$.

Clinically successful results were achieved in eight of the nine patients $(89 \%)$ who underwent continuous negative intraluminal aspiration, and all (100\%) were fully recovered at discharge.

One male patient who underwent laparoscopic Ivor Lewis esophagectomy after neoadjuvant CRT due to esophageal cancer developed esophagomediastinal and tracheomediastinal fistulas and died on postoperative day 20 (Figures 2-8).

Clinical success was achieved in five of six patients (83\%) who developed fistula/leakage in the upper GI tract, whereas clinical success was achieved in all three patients (100\%) who developed a fistula or leakage in the lower GI tract.

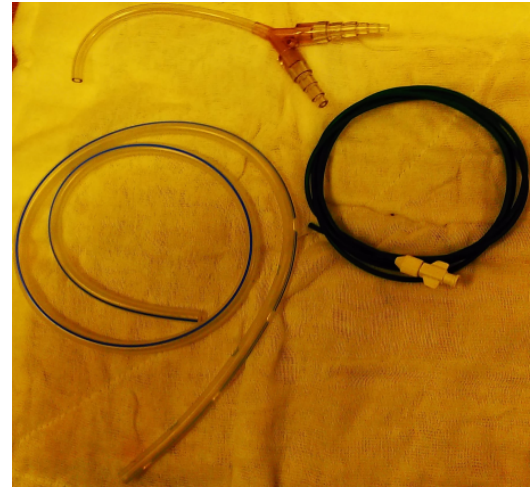

Figure 2. The materials used to form the negative aspiration system.

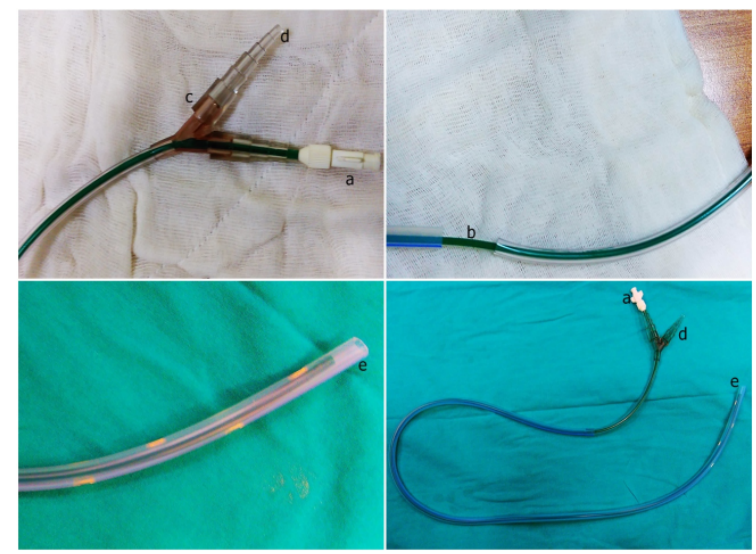

Figure 3. The photographic appearance of the material used in the aspiration system. (a) Air duct; (b) ERCP catheter; (c) Y adaptor separated from the hemovac drain system; (d) Continuous aspiration channel; (e) NG catheter tube.

\section{Discussion}

Invasive methods are commonly used to treat fistulas and complications due to anastomotic leakage that develop after surgery for many benign and malignant GI diseases, which previously had only one treatment [5-12]. Because of the high morbidity and mortality of patients with a fistula and/or anastomotic leakage, the search for treatments has continued due to the lack of a demonstrably effective method.

Providing total parenteral nutritional support and restricting oral intake decreases morbidity and mortality in these patients [13-15]. Other studies have reported that antibiotic therapy and medical treatments that decrease GI tract secretions, such as somatostatin, are useful to treat these same patient groups $[16,17]$.

In 1984, Levy et al. published a case series of 23 patients who underwent continuous intraluminal infusion and aspiration to treat postoperative peritonitis caused by gastric and duodenal fistulas. In the same year, Thorson et al. published a study on transrectal drainage of lower colonic anastomotic leakage $[18,19]$. In 1966, Infante et al. reported transluminal endoscopic drainage of esophageal leakage to the mediastinum or pleural area [20]. 
Kale et al. studied five patients with duodenal fistulas who underwent continuous negative intraluminal aspiration for the first time, with the results being published in 1998 [21].

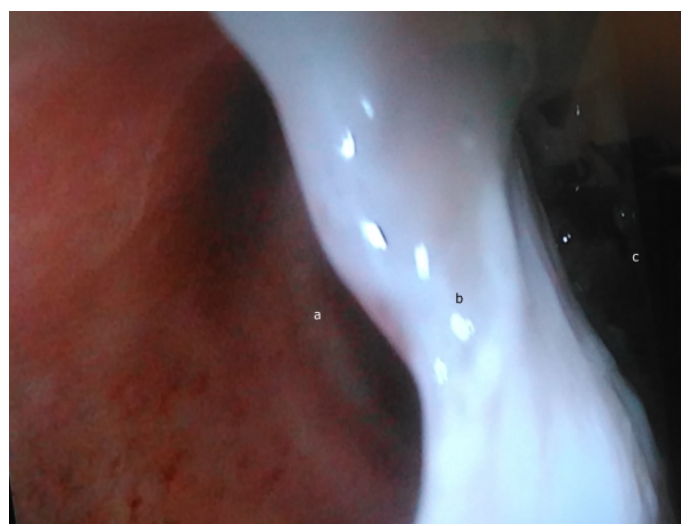

Figure 4. Bronchomediastinal fistula close-up view; (a) Tracheal cartilage parts; (b) Membranous part of the trachea; (c) Mediastinum.

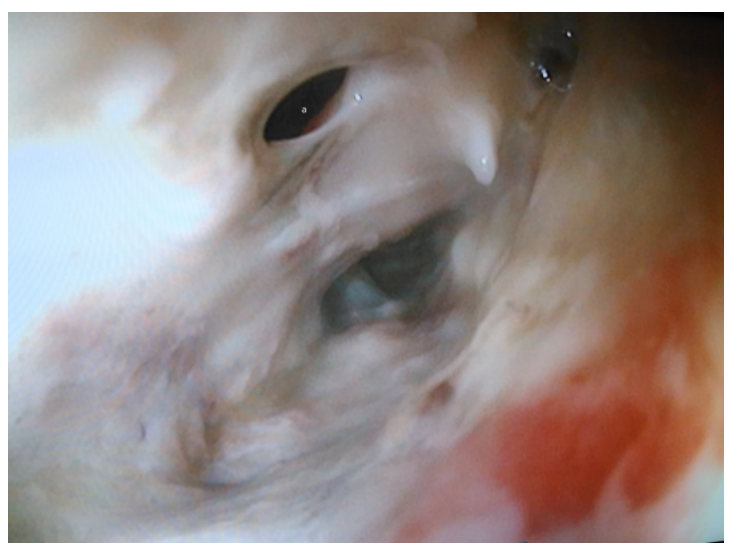

Figure 5. The pouch mediastinum. (a) Bronchomediastinal fistula.

Subsequently, surgeons have published results following small changes to the endoscopic continuous aspiration method [22-24].

Stents or clips, band ligation, and injection of tissue adhesive agents have become popular methods to treat fistulas and an anastomotic leakage [5-12]. Several methods of nonsurgical fistula closure have been attempted but none has been proved in a randomized, prospective trial.

For example, the injection of fibrin glue, other injectable treatments include histoacryl glue into the fistula tract, porcine small intestinal submucosa has been used less commonly, in small bowel fistulas [25,26].

However, complications, such as moderate, medium, or serious chest pain, bleeding, stent folding, pneumomediastinum, esophago-tracheal fistula, obstruction of the stent with food, and tracheal pressure have been reported after placing stents in the GI system [27-29].

Inserting a stent can also lead to serious morbidity and mortality due to stent migration and perforation [30]. The high cost is another disadvantage, and none of these issues were present when performing continuous negative aspiration on our patients.

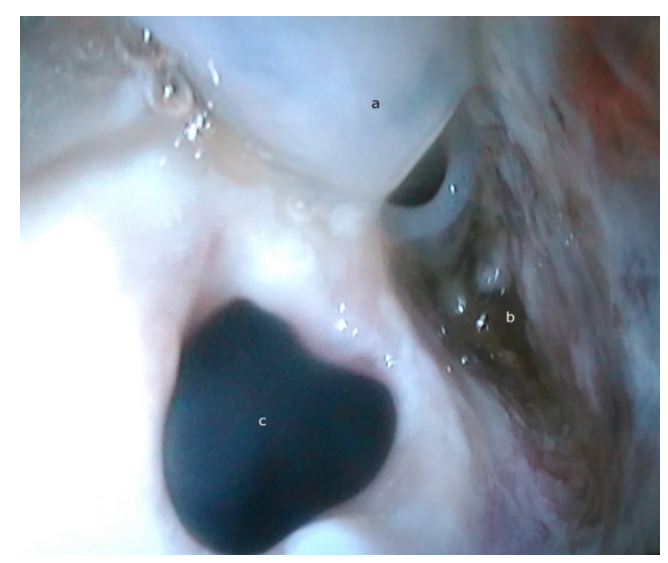

Figure 6. The drainage of the pouch related bronchomediastinal fistula by a naso-oesophago-mediastinal tube catheter. (a) Catheter; (b) Meadiastinal pouch; (c) Bronchomediastinal fistula.

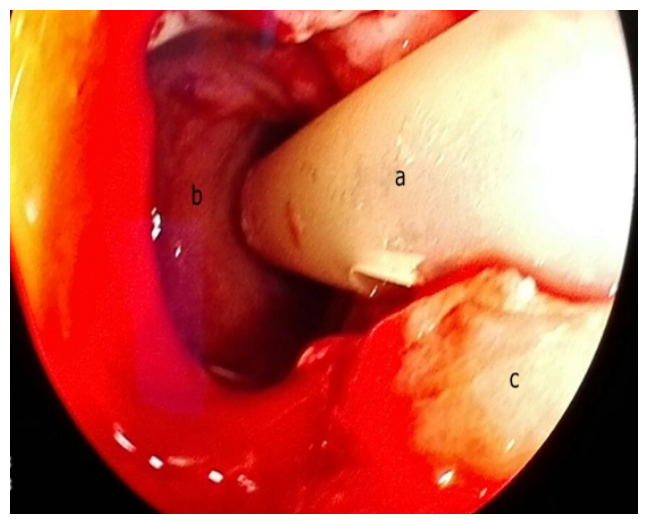

Figure 7. Treatment of anastomotic leakage in the rectum by negative aspiration system; (a) Catheter; (b) Colon lumen; (c) Partially healed fistula pouch.

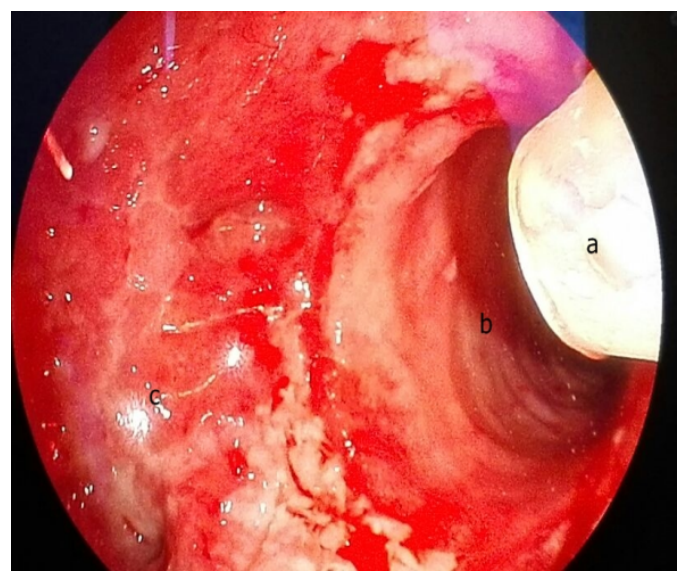

Figure 8. Anastomotic leakage in the rectum healed by negative aspiration system; (a) Catheter; (b) Colon lumen; (c) Healed fistula pouch.

Our application is simple and effective and can be performed with easily accessible materials at a low cost in every healthcare organization in which endoscopic operations are performed. Similar to a stent, our continuous negative 
aspiration method is limited to endoscopically accessible areas in the GI tract. In addition, oral intake in patients who have undergone conducted continuous negative aspiration cannot start until $13 \mathrm{~d}$ after the procedure, whereas patients who receive a stent can eat orally 1-2 d later [31]. Similarly, our method does not have the same wide indication area as that of the stent, such as for an intestinal obstruction or stenosis.

Stents or surgery is preferred for esophagobronchial and esophagomediastinal fistulas. Preoperative requirements may take up to 6 months to fulfil, and it is not unreasonable to wait that long to progress to definitive surgical intervention [32]. Recommendations vary but usually specify waiting 3 to 6 months or longer after the original operation [31-33].

The success of our negative aspiration system, particularly for lateral fistulas, is due to continuous aspiration inside the intestinal lumen decreasing pressure and increasing the flow of liquid contents outside the lumen. We noticed this affect due to the dramatic decrease in drainage volume when we started intraluminal aspiration on our patients with an upper GI tract fistula. The method decreases leakage of GI contents outside the lumen, and the decreased size of the abscess pouch in the area and recovery of the fistula shortens hospitalization duration.

The situation is similar in patients with a rectal leakage, although these patients have a deflector ileostomy so the GI contents do not reach the anastomotic leakage site. However, an abscess emerging around the anastomosis can lead to serious septic complications. In these patients, the doublelumen catheter placed in a transanal position, along with the negative pressure applied, drains the perianastomotic abscess, which helps the abscess pouch shrink and the fistula defect to recover.

In summary, although only nine patients were evaluated in this study, the continuous intraluminal aspiration method was very effective, cost efficient, reliable, minimally invasive, and successful for treating fistulas and anastomotic leakage in a short period and with a low complication rate.

\section{Conclusion}

Reoperations for intestinal fistulas and anastomotic leakage result in high morbidity and mortality. Thus, non-surgical methods with lower mortality and morbidity rates are preferred for a reoperation. Although this was a low volume retrospective study, the treatment success rate is notable. This aspiration method using a continuous intraluminal doublelumen catheter is relatively longer in duration but is costeffective and results in a low mortality rate in appropriate cases. More extensive studies should be performed with more patients to determine the effectiveness of this method and render it widely applicable.

\section{Conflicts of Interest}

The authors have no financial conflicts of interest.

\section{References}

1. Shin JH, Kim JH, Song HY. Interventional management of esophagorespiratory fistula. Korean J Radiol 2010; 11: 133-140.

2. Nguyen SQ, Divino CM, Vine A, Reiner M, Katz LB, Salky B. Laparoscopic surgery for diverticular disease complicated by fistulae. JSLS 2006; 10: 166-168.

3. Zhou N, Chen WX, Li YM, Xiang Z, Gao P, Fang Y. Successful tubes treatment of esophageal fistula. J Zhejiang Univ Sci B 2007; 8: 709-714.

4. Mabrut JY, Druez P, Goncette L, Fiasse R, Collard JM. Drainage-lavage and closure of a late esophageal perforation with esophagopleural fistula and encysted pleural effusion after endoscopic injection sclerotherapy for varices. Gastroenterol Clin Biol 2003; 27: 1031-1034.

5. Richardson J, Richardson M, Nijjar R. Fistula after pyloroplasty-A novel approach to the management of a leak following oesophagectomy. J Surg Case Rep 2012; 1: 9.

6. Abu Dayyeh BK, Jirapinyo P, Weitzner Z, Barker C, Flicker MS, Lautz DB, Thompson CC. Endoscopic sclerotherapy for the treatment of weight regain after Rouxen-Y gastric bypass: outcomes, complications, and predictors of response in 575 procedures. Gastrointest Endosc 2012; 76: 275-282.

7. Zhang Y, Chen Y, Qu CY, Zhou M, Ni QW, Xu LM. Effects of medical adhesives in prevention of complications after endoscopic submucosal dissection. World J Gastroenterol 2013; 19: 2704-2708.

8. Han JH, Lee TH, Jung Y, Lee SH, Kim H, Han HS, Chae H, Park SM, Youn S. Rescue endoscopic band ligation of iatrogenic gastric perforations following failed endoclip closure. World J Gastroenterol 2013; 19: 955-999.

9. Mönkemüller K, Peter S, Alkurdi B, Ramesh J, Popa D, Wilcox CM. Endoscopic closure of a gastrocolic fistula using the over-the-scope-clip-system. World J Gastrointest Endosc 2013; 5: 402-406.

10. Yu DW, Hong MY, Hong SG. Endoscopic treatment of duodenal fistula after incomplete closure of ERCP-related duodenal perforation. World J Gastrointest Endosc 2014; 6: 260-265.

11. Goenka MK, Goenka U. Endotherapy of leaks and fistula. World J Gastrointest Endosc 2015; 7: 702-713.

12. Rogalski P, Daniluk J, Baniukiewicz A, Wroblewski E, Dabrowski A. Endoscopic management of gastrointestinal perforations, leaks and fistulas. World J Gastroenterol 2015; 21: 10542-1052.

13. Bleier JI, Hedrick T. Metabolic support of the enterocutaneous fistula patient. Clin Colon Rectal Surg 2010; 23: 142-148.

14. Dudrick SJ, Panait L. Metabolic consequences of patients with gastrointestinal fistulas. Eur J Trauma Emerg Surg 2011; 37: 215-225.

15. Polk TM, Schwab CW. Metabolic and nutritional support of the enterocutaneous fistula patient: a three-phase approach. World J Surg 2012; 36: 524-533. 
16. Głuszek S, Korczak M, Kot M, Matykiewicz J, Kozieł D. Digestive system fistula: a problem still relevant today. Pol Przegl Chir 2011; 83: 32-41.

17. Fan YP, Ren JA, Zhao YZ, Gu GS, Zhao K, Li JS. Fistula output microorganism-susceptible antimicrobial prophylaxis is associated with a lower risk of surgical site infection in gastrointestinal fistula patients undergoing onestage definitive surgery. Surg Infect (Larchmt) 2014; 15: 774-780.

18. Levy E, Cugnenc PH, Frileux P, Hannoun L, Parc R, Huguet C, Loygue J. Postoperative peritonitis due to gastric and duodenal fistulas. Operative management by continuous intraluminal infusion and aspiration: report of 23 cases. Br J Surg 1984; 71: 543-546.

19. Thorson AG, Thompson JS. Transrectal drainage of anastomotic leaks following low colonic anastomosis. Dis Colon Rectum 1984; 27: 492-494.

20. Infante M, Valente M, Andreani S, Catanese C, Dal Fante M, Pizzetti P, Giudice G, Basilico M, Spinelli P, Ravasi G. Conservative management of esophageal leaks by transluminal endoscopic drainage of the mediastinum or pleural space. Surgery 1996; 119: 46-50.

21. Tanık A, Kale IT, Kuzu A, Bostanc1 B, Yilmaz U. Duodenal fistüllerin intralüminal devamlı aspirasyon ile tedavisi. Management of duodenal fistula by intraluminal continuous aspiration. Ulusal Cerrahi Dergisi 1998; 14: 284-288.

22. Mennigen R, Senninger N, Laukoetter MG. Novel treatment options for perforations of the upper gastrointestinal tract: endoscopic vacuum therapy and overthe-scope clips. World J Gastroenterol 2014; 20: 7767-7776.

23. Bludau M, Hölscher AH, Herbold T, Leers JM, Gutschow C, Fuchs H, Schröder W. Management of upper intestinal leaks using an endoscopic vacuum-assisted closure system (E-VAC). Surg Endosc 2014; 28: 896-901.

24. Möschler O, Nies C, Mueller MK. Endoscopic vacuum therapy for esophageal perforations and leakages. Endosc Int Open 2015; 3.

25. Dalton D, Woods S. Successful endoscopic treatment of enterocutaneous fistulas by histoacryl glue. Aust NZ J Surg 2000; 70: 749-750.

26. Xiuwen W, Jianan R, Gefei W, Jianzhong W, Feng W, Yueping F, Yuanxin L, Gang H, Yanbing Z, Xiaofei S, Bin
Q, Min Y, Jieshou L. Evaluating the use of fibrin glue for sealing low-output enterocutaneous fistulas: study protocol for a randomized controlled trial. Trials 2015; 16: 445.

27. Raimondo D, Sinagra E, Facella T, Rossi F, Messina M, Spada M, Martorana G, Marchesa PE, Squatrito R, Tomasello G, Lo Monte AI, Pompei G, La Rocca E. Selfexpandable metal stent placement for closure of a leak after total gastrectomy for gastric cancer: report on three cases and review of the literature. Case Rep Gastrointest Med 2014; 2014: 409283.

28. Dobrucali A, Caglar E. Palliation of malignant esophageal obstruction and fistulas with self-expandable metallic stents. World J Gastroenterol 2010; 16: 5739-5745.

29. Kujawski K, Stasiak M, Rysz J. The evaluation of esophageal stenting complications in palliative treatment of dysphagia related to esophageal cancer. Med Sci Monit 2012; 18: 323-329.

30. Almadi MA, Bamihriz F, Aljebreen AM. Fatal aortoesophageal fistula bleeding after stenting for a leak post sleeve gastrectomy. World J Gastrointest Surg 2013; 5: 337-340.

31. Jae JH, Yeon SJ, Young SP, Hyuk Y, Cheol MS, Nayoung K, Dong HL. Comparison of endoscopic vacuum therapy and endoscopic stent implantation with self-expandable metal stent in treating postsurgical gastroesophageal leakage. MD Med (Baltimore) 2016; 95.

32. Kaushal M, Carlson GL. Management of enterocutaneous fistulas. Clin Colon Rectal Surg 2004; 17: 79-88.

33. Galie L, Charles BW. Postoperative enterocutaneous fistula: when to reoperate and how to succeed. Clin Colon Rectal Surg 2006; 19: 237-246.

\section{*Correspondence to}

Arif Emre

Faculty of Medicine

Kahramanmaras University

Kahramanmaras

Turkey 